\title{
Multicentric Osteolysis, Nodulosis, and Arthropathy
}

National Cancer Institute

\section{Source}

National Cancer Institute. Multicentric Osteolysis, Nodulosis, and Arthropathy. NCI

Thesaurus. Code C123437.

A rare, autosomal recessive inherited syndrome caused by mutations in the MMP2 gene.

It is characterized by the presence of multiple, painless subcutaneous nodules, osteolysis particularly in the hands and feet, osteoporosis, and arthropathy. 